\title{
Lactational Exposure to Fipronil Pesticide in Low Dose Impairs Memory in Rat's Offspring
}

Francisco Pizzolato Montanha ${ }^{1}$, Faber Daniel Machado ${ }^{2}$, Caique Aparecido Faria ${ }^{2}$, Fábio Anselmo ${ }^{3}$, Rômulo Francis Estangari Lot ${ }^{4}$, Raquel Beneton Ferioli ${ }^{1}$, Noeme Sousa Rocha ${ }^{1}$ and Antonio Francisco Godinho ${ }^{3^{*}}$

${ }^{1}$ Faculdade de Medicina Veterinária e Zootecnia, Universidade Estadual Paulista, (UNESP), Paulista State University, Júlio de Mesquita Filho, Botucatu - SP, Brazil

${ }^{2}$ Faculdade do Sudoeste Paulista (FSP), Jardim Europa I, Avaré - SP, Brazil

${ }^{3}$ Center of Toxicological Assistance (CEATOX), Biosciences Institute, Universidade Estadual Paulista (UNESP), Paulista State University, Campus of Botucatu - SP, Brazil

${ }^{4}$ Universidade de Marilia (UNIMAR), Campus Universitário, Marília - SP, Brazil

*Corresponding author: Antonio Francisco Godinho, Center of Toxicological Assistance (CEATOX), Biosciences Institute, Universidade Estadual Paulista (UNESP), Paulista State University, Campus of Botucatu, SP, Brazil, Tel: +55 143815 3048; E-mail: godinho@ibb.unesp.br

Rec date: Jun 17, 2016; Acc date: Jul 14, 2016; Pub date: Jul 16, 2016

Copyright: () 2016 Montanha FP. This is an open-access article distributed under the terms of the Creative Commons Attribution License, which permits unrestricted use, distribution, and reproduction in any medium, provided the original author and source are credited.

\begin{abstract}
Perinatal exposure to pesticides has been associated with neurotoxic changes that may occur during offspring development. This work aimed to evaluate the memory behavior in young and adult offspring from Wistar rats exposed to fipronil in the lactational period. For this, pregnant rats were distributed into two groups $(\mathrm{N}=15)$ constituted as follows: control (Ct) and exposed to fipronil (Fip). Fipronil (Topline ${ }^{\circledR}$ ) was administrated to mothers topically, at dose of $1 \mathrm{mg} / \mathrm{kg} / \mathrm{day}$, from the 7-14th day of lactation. The offspring memory behavior was assessed using the new object recognition task (ORT) and eight-radial arm maze task (8-RAM). Additionally was quantified the activity of the acetylcholinesterase enzyme (AChE) and made histopathological analysis of brain tissue. Results show persistent decreased memory behavior in offspring exposed to fipronil during lactation period associated with altered AChE activity and morphological changes in the animal's brain tissue. It is concluded that lactational exposure to fipronil provoked damage to the central nervous system (CNS) including altered memory behavior with histopathological and biochemical changes.
\end{abstract}

Keywords: Fipronil; Memory; Behavior; Ache; Lactational exposure

\section{Introduction}

Pesticides are widely used in developing countries and their use in agriculture and public health impacts environment, through soil, water and food contamination, and reaches humans through occupational and indirect exposure. In this situation, supposed pesticides selectiveness among target organisms it may be lost and health problems for humans are being enhanced in recent decades.

The contact, principally at long-term with pesticides, through environmental or occupational exposure impacts human life and disrupt the function of different organ systems in the body including the nervous, endocrine, immune, reproductive, renal, cardiovascular, hepatic and respiratory tissues $[1,2]$.

Fipronil - pesticide [( \pm )-5-amino-1-(2,6-dichloro- $\alpha, \alpha, \alpha$-trifluoro-ptolyl)-4 trifluoromethylsulfinylpyrazole-3-carbonitrile] is the first member of the phenylpyrazole insecticide class, which has a broad spectrum of activity against insects [3]. It was rapidly adopted as an insecticide for use in agriculture [4] and veterinary [5].

Although it has been designated by Environmental Protection Agency (EPA) as an alternative to the use of organophosphates, several questions about the fipronil adverse effects on public health were raised [3,5]. Additionally, the main metabolite sulfone and its photodegradation product de-sulfinil were reported to be more toxic to insects, mammals, fish and birds than the parent compound [6].
Behavioral investigations contribute to enhance the risk assessment for pesticides and might be very important in cases when animals or humans are exposed to low doses. Animal's behavior is a product of process integration as cognitive, sensory, motor, and various others functions associated with the nervous system [7]. Recently, it was demonstrated in our laboratories that acute fipronil exposure interferes with neurobehavioral activity in rats [8].

On other hand, it has been suggested that GABA may be related to processes of memory formation [9] and there are also some studies regarding the relevance of GABA to the processes of learning and memory behaviors [10]. The fact of chemical injury to the CNS can change the phases of acquisition, consolidation and recall of the memory [11] contributes to raise questions about GABAergic system involvement. In this sense it was recently demonstrated that reduction of GABA in the prefrontal cortex caused a delay in the activities done by monkeys [12-14].

Although fipronil target glutamate-activated chloride channels present in insects, suggesting a selective action mechanism, it also targets GABAergic receptors present in humans and animals $[15,16]$ Recent work of our research group shown that memory impairment due to fipronil pesticide exposure occurs at the GABAA receptor level, in rats.

Besides GABA, acetylcholine (ACh) neurotransmitter also has long been implicated in cognitive functions. ACh plays important function in memory formation in the hippocampus, as evidenced by impaired learning after administration of antagonists to their respective receptors [17]. Additionally, substantial evidence implicates ACh in the 
acquisition of object memories [18-20]. One hypothesis to be tested is that fipronil can modulate memory behavior by interfering simultaneously with the GABAergic and cholinergic systems.

Central nervous system development occurs both in utero and postnatally, and requires an adequate environment. It depends of a complex relation between different factors that have different spatial and temporal roles. Disturbances of development may have genetic as well as external factors acting during any of the phases of development [21].

Recent scientific reports has drawn attention and have shown that there is a relation between use of pesticides and neurodevelopmental disorders in children when exposure occur in pre and perinatal periods [22-24]. In this sense, a reported passage of both, fipronil and it metabolite fipronil sulfone, through the milk in domestic animals [25] increasing concerns regarding exposure on these critical periods.

The absence of systematic studies on the long-term consequences of perinatal pesticide exposure seems risk, especially in the case of pregnant women, their fetuses, and suckling babies. In the case of pregnancy, the lack of routine biological environmental monitoring at the workplace and other preventive measures for the workers' protection in certain professions, such as agricultural workers or in families living near agricultural crops, contribute to real pesticides neurotoxicity risks for these people.

As fipronil acts as a GABAergic antagonist modulating cognitive functions it is important to investigate the hypothesis of that its neurotoxic action could interferes with the memory behavior during developmental period.

Thus, the aim of this study was to evaluate memory behavior in offspring from females rats exposed to fipronil during lactational period. Due to the relation between memory processes and ACh activity, a possible link with fipronil exposure was investigated using acetylcholinesterase enzyme activity as biomarker.

\section{Materials and Methods}

All procedures for animal experimentation were approved by the institutional Ethics Committee on Animal Use of Faculty of Medicine Veterinary (FMVZ), Paulista State University (UNESP), which is complied with international guidelines for the use of experimental animals.

\section{Animals}

Thirty females and ten males Wistar rats, acquired with 22 day-old from our institutional colony were kept under standard conditions (up to four rats per cage, controlled temperature of $21 \pm 2{ }^{\circ} \mathrm{C}$ and $70 \%$ humidity, 12-h light/dark cycle starting at 6 a.m. with light, continuous exhaustion, receiving water and food ad libitum) until they reached 80 days of age.

\section{Experimental procedure}

The animals were mated placing, in the same cage, three females and one male. Females with sperm presence in the vaginal smear were considered pregnant (considered zero-day of gestation period - PND0) and were separated in isolated cases. Pregnant females were randomly assigned into 2 groups of 15 animals named control (Ct) and fipronil (Fip), and were weighed every 3 days. At birth litters were adjusted to eight pups per mother to standardize the litter size and maintained with it, throughout the lactation period, until the 21 postnatal day-old (PND21).

For the experiments, the Topline ${ }^{\bullet}$ (Merial of Brazil) containing fipronil as active ingredient ( $1 \%$ concentration) was used. Fipronil was administered topically to mothers (dorsal region of the neck, after shaving), $1 \mathrm{mg} / \mathrm{kg} / \mathrm{day}$, from the $7-14^{\text {th }}$ day of lactation. Control mothers received topically, by the same period, administration of 0.2 $\mathrm{ml}$ of corn oil (to allow adherence of control solution to the skin). For the formation of groups for behavioral assessment only one male pup of each mother was used, totalling fifteen animals for each experimental group ( $\mathrm{Ct}$ and Fip). To evaluate influence of toxicity versus developmental stage, assessments of pups were made at PND23 (young), PND65 (young to adult) and PND80 (adult) ages, according to the experimental design.

The fipronil dose utilized in present experiment it can be considered very low, since the reported LD50 dose for fipronil technical-grade product is greater than $2000 \mathrm{mg} / \mathrm{kg}$ (rat, dermal) and reported LD50 doses for fipronil veterinary product formulations are greater than $2000 \mathrm{mg} / \mathrm{kg}$ (rabbit, dermal) [25,26].

\section{Behavioral assessment}

For memory assessment was used the novel object recognition task according Dix and Aggleton [27], in young (PND23) and adults (PND80) pups, and the eight radial arm maze task according Olton [28], in young to adult (PND65) pups.

The ORT assessment used an open field arena built in white timber, waterproof, measuring $40 \times 25 \times 15 \mathrm{~cm}$ for young and $58 \times 43 \times 39 \mathrm{~cm}$ for adults. For tests rats were subjected to a habituation session on the arena for 5 minutes. The following day the rats returned to the arena to a new training session for 5 minutes being presented now to a two identical objects of wood (A1 and A2), similar in size, color and texture, and having equal shapes. The objects were positioned in two adjacent corners of the box and at $9 \mathrm{~cm}$ of the walls. To assess shortterm memory retention task (STM), 1.5 hours after the training session, rats were placed to explore the arena for 5 minutes in the presence of two objects: the familiar object $\mathrm{A}$ and a novel object $\mathrm{B}$, placed in the same locations as in training period. To assess long-term memory retention task (LTM), 24 hours after training session, rats were placed to explore the arena for 5 minutes in the presence of the familiar object A and now a third different novel object C. Exploration was defined as the time spent in sniffing or touching the object with the nose, sit on the object was not considered exploration. The same animals were used for the testing of STM and the LTM. At the end of each session with an animal the apparatus was cleaned with cotton soaked in ethyl alcohol $(5 \%, \mathrm{v} / \mathrm{v})$ to eliminate traces of the animal predecessor. Using the data obtained about the exploration of three distinct objects, a new object recognition index (NORI) for each animal was calculated as the rate $\mathrm{TN} / \mathrm{TN}+\mathrm{TF}$ ( $\mathrm{TF}=$ time spent exploring the familiar object $\mathrm{A}$, and $\mathrm{TN}=$ time spent exploring the novel object B or C) $[27,28]$.

The 8-RAM assessment used an octagonal radial maze built in white timber, waterproof, and consisted of a central circular platform $(20 \mathrm{~cm}$ high $\mathrm{x} 47 \mathrm{~cm}$ diameter) coupled to eight identical arms of the same size $(47 \times 11 \times 18 \mathrm{~cm})$, symmetrically distributed around it, all covered with transparent acrylic. In the first day animals were placed directly in the central platform of apparatus for five minutes to recognize it. On the second day of training the animals became for 15 minutes in the apparatus independently of the number of visited arms, to recognize it. 
From the subsequent four days, each animal made training sessions for free arms recognition. The animals were withdrawn from the labyrinth until complete one visit in each arm or have completed 15 minutes in the apparatus. Finally, rats previously placed fasting were trained to find a solid food portion placed at the end of one of the arms (always the same). In the room for experimentation, in a round of the 8-RAM apparatus, runways were kept in each wall, which served as the animal's spatial orientation for preferential entry into any of the arms. Entry in an arm was considered as walk from the central circular platform until the end of the arm extension. For the memory task, the animal was placed in the end of a prefixed arm, different from that of training period, and should meet and interact with food. As memory parameters were recorded: (a) latency time to find food, (b) number of arms visited incorrectly, (c) number of arms revisited. At the end of each session with an animal apparatus was cleaned with cotton soaked in ethyl alcohol $(5 \%, \mathrm{v} / \mathrm{v})$ to eliminate traces of the animal predecessor.

Observations in both apparatus, ORT and 8-RAM, were filmed for subsequent quantification of each behavior exhibited by animals.

\section{Biochemical and histopathological evaluation}

After behavioral testing the animals were anesthetized with xylazine + ketamine solution, i.p., to collect blood by direct cardiac puncture, and then animals were decapitated to collect the brain.

The blood was centrifuged at 2,500 rpm for 5 minutes and the serum collected was used for spectrophotometric dosage (Spectrophotometer Ultrospec 2000-Pharmacia Biotech) of AChE activity (Biotech kit - Brazil).

For histopathological evaluation brains were collected (of young and adult rats) and fixed in buffered $10 \%$ formalin solution 72 hours and then, processed into histological cassettes to produce paraffin blocks. From these were obtained $4 \mu \mathrm{m}$ thick sections and mounted consecutively on histological glass slides for this purpose. The slides were stained with Hematoxylin and Eosin (HE) and evaluated microscopically.

\section{Statistical analysis}

The results are expressed as means \pm S.E.M. Shapiro-Wilk test was applied to verify normality of data distribution. Comparisons between groups were assessed by Student's paired t-test with Bonferroni's correction post hoc test, $t$-distribution and degree of freedom (df) values. For analyze of results was used Graph Pad Prism ${ }^{\bullet} 6.0$ for Windows (San Diego, CA, USA). Differences were considered significant when $\mathrm{P}<0.05$ [29].

\section{Results}

There were not observed in pregnant mothers obvious clinical signs suggesting intoxication by fipronil and change in weight gain during pregnancy (data not shown).

Assessment of the young pups in ORT task, using Novel Object Recognition Index (NORI), showed that there was no significant difference $(p>0.05)$ between the groups analyzed for STMJ (data not shown), however, for STMA, Fip group significantly decreased $(\mathrm{p}<0.05)$ the NORI compared to control (Figure 1A). For LTMJ, Fip group significantly decreased $(\mathrm{p}<0.05)$ the NORI compared to control (Figure 1B). For LTMA, Fip group significantly decreased $(\mathrm{p}<0.001)$ the NORI compared to control (Figure 1C).

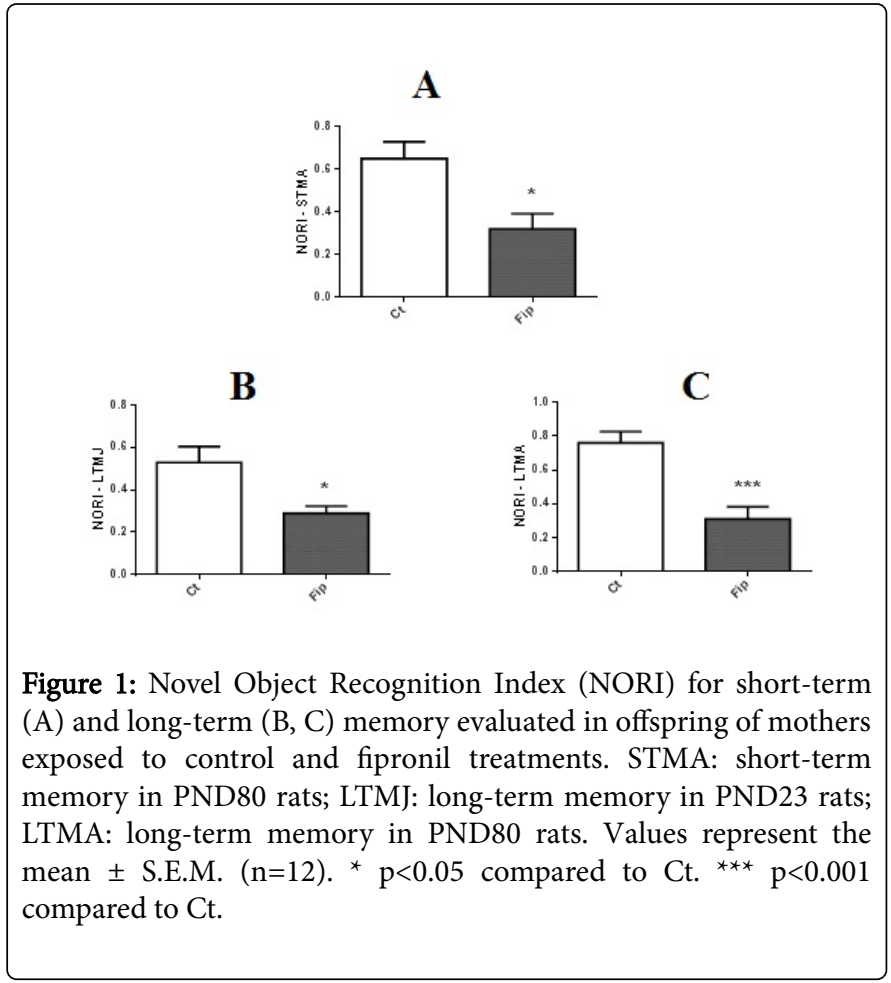

In 8-RAM it was observed that the PND65 pups of fipronil group had a significant increase $(\mathrm{p}<0.05)$ in latency time to find food compared to control group (Figure 2A), demonstrating a failure in memory behavior. Figure 2B shows that PND65 offspring of Fip group had a significant increase $(\mathrm{p}<0.05)$ in number of incorrectly visited arms compared to control. This result to confirm the failure in memory previously observed. Figure $2 \mathrm{C}$ indicate that there was a significant increase $(\mathrm{p}<0.05)$ in the number of incorrect revisitations in the arms of maze in PND65 offspring of Fip group compared to control.
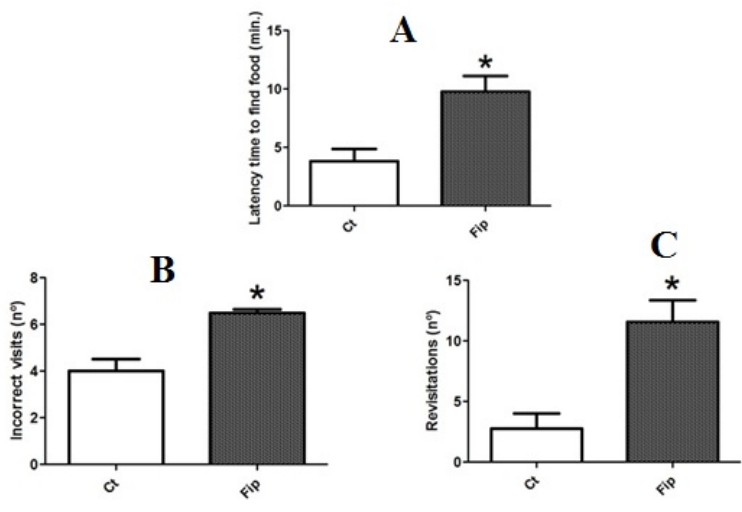

Figure 2: Results of 8-RAM assessment in PND65 offspring of mothers exposed to control and fipronil treatments. Latency time to find food (A); number of visits to incorrect arms (B); number of incorrect arms revisited (C). Values represent the mean \pm S.E.M. $(\mathrm{n}=12) .{ }^{\star} \mathrm{p}<0.05$ compared to $\mathrm{Ct}$. 
In the results of AChE activity assessment it is observed that there was no significant difference $(\mathrm{p}>0.05)$ between the Fip and control group for PND23 pups (data not shown) but in PND65 pups is observed that rats of the Fip group had a statistically significant increase $(\mathrm{p}<0.05)$ in the AChE activity compared to Ct group (Figure 3).

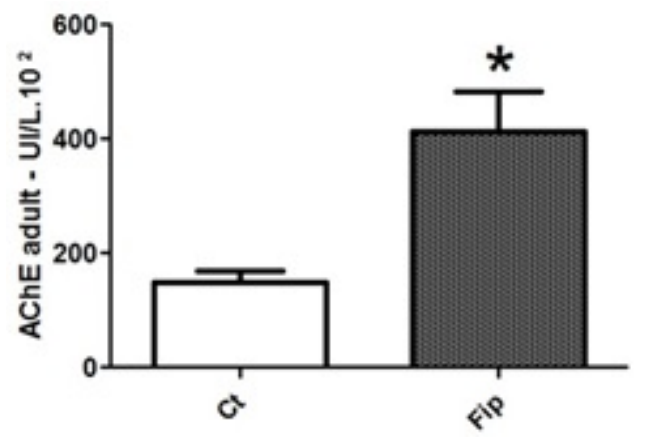

Figure 3: Dosage of acetylcholinesterase enzyme activity in serum of adult offspring (PND80) of mothers exposed to control and fipronil treatments. The values represent the mean \pm S.E.M. $(n=12)$. * $\mathrm{p}<0.05$ compared to $\mathrm{Ct}$.

Table 1 and Figures 4A - 4C represent the observations obtained in the histopathological assessment in the brains of offspring. In the adult animals (PND60) of the Fip group vascular congestion from moderate to intense degree was observed. The control group did not show this change (Table 1 and Figure 4A). There was presence of edema (Figure
$4 \mathrm{~B})$ in histological sections from the brains of young (PND23) and adult (PND60) offspring exposed to fipronil. In the young, the Fip group showed this change from moderate to intense. In adults, the change was from slight to moderate in $\mathrm{Ct}$ and Fip groups (Table 1). Except for the group Ct (young), all groups showed vacuolization (Figure $4 \mathrm{C}$ ) in the CNS. In the young rats from Fip group the change was from moderate to intense. In adults, Ct group had change from mild to moderate and Fip group, intense change (Table 1).

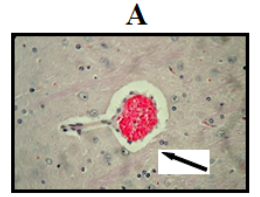

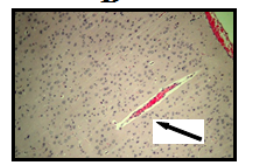

C

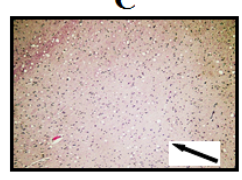

Figure 4: Representative histological evaluation in brains of offspring's of mothers exposed to fipronil, relative to the intensity of the alterations observed. A- vascular congestion. $400 \mathrm{x}$ magnification. B-edema. 100x magnification. C-Vacuolization. 40x magnification.

\begin{tabular}{|l|l|l|l|l|}
\hline \multirow{2}{*}{ Pathological change } & \multicolumn{2}{l|l|}{ PND23 offspring } & \multicolumn{2}{l|}{ PND80 offspring } \\
\cline { 2 - 6 } & Ct & Fip & Ct & Fip \\
\hline Vascular congestion & + & n.c. & n.c. & +++ \\
\hline Edema & n.c. & +++ & ++ & ++ \\
\hline Vacuolization & n.c. & +++ & ++ & +++ \\
\hline
\end{tabular}

Table 1: Histopathological changes in the brain of the offspring of mothers exposed to control and fipronil treatment. [Note: n.c. (no change); + (slight change); ++ (light to moderate change); +++ (moderate to intense alteration); ++++ (Intense alteration)].

\section{Discussion}

Results of experiments showed that exposure to fipronil during lactation period caused changes in the memory behavior of the young and adult offspring, indicating that the offspring neurobehavioral development was impacted by fipronil.

In experiments using perinatal exposure, changes in the mother, such as weight loss or changes in maternal homeostasis, may interfere indirectly with the development of offspring [30-33]. The nonoccurrence of maternal toxicity seen in present experiment indicates that any change occurring with the offspring' was therefore exclusively due to exposure to fipronil.

According to previous literature data exposure to pesticides during pregnancy and lactation can cause changes reflected in physical and behavioral offspring aspects, according to the period of animal development $[33,34]$. Perinatal exposure may involve latent effects which are only observed later, even in cases in which exposure occurs at doses below those which promote evident effects in adults [35].

In the present experiment 8-RAM assessment shows increase in the latency time to find food, in the number of incorrect visits and in the number of arms revisitations. These results clearly demonstrating a defective memory behavior in the offspring exposed to fipronil.

Memory is the retention of information learned [36], and a process that requires the integrated activity of different brain regions and neurotransmitter systems [37]. Learning can be defined as the mechanism by which new information or knowledge is acquired, that is, the acquisition of new information, and the first stage of memory [36]. Toxic chemical injuries on CNS affect the phases of the acquisition, consolidation and evocation of memory. Memory consolidation occurs primarily in the hippocampus [38], being the GABAergic system fundamental for both development and maintenance of the memory in this area [17,39]. As Fip exerts 
antagonistic action on GABA receptor a hypothesis for explanation should be that Fip provoked memory impairment acting on hippocampus area.

According to studies by Stanley et al. [17] when lesions that include the hippocampus are greater than $75 \%$, memory is significantly impaired. Despite of the morphological evaluation in this study not be conducted specifically for the hippocampus, the lesions provoked in the rat brain by Fip, corroborate with the statement of these authors.

In the study of cognitive memory using the ORT task there was no significant difference between the groups analyzed for the STM in young rats. However, for the LTM the young rats of Fip group showed a significant decrease compared to the CT group. In adult offspring, there was a significant decrease in the short- and long-term memory in Fip group compared to controls. The results with ORT confirm, in certain way, the results obtained in the 8-RAM with the spatial memory and seem to suggest an 'imprinting' effect by fipronil.

The tasks of ORT and 8-RAM are especially suitable for testing the effects of pharmacological interventions and chemical agents on learning and memory. What is new induces excitement and have motivational effects that are used as a reinforcement to induce learning [38].

According McEown and Treit [40] drugs which activate the GABAergic system promote impairment in memory formation when administered into the lateral ventricle, basal forebrain, hippocampus and amygdala. Our results appear to suggest the opposite, since fipronil is inhibitory on GABA system. These differences can be caused by the form and way of administration, once McEown and Treit made direct administration in specific locations of the CNS, while our results are due to systemic exposure.

In rodents, the tasks to access the memory recognition of a new object are based on the natural tendency of animals to explore what is new [41]. From the further exploration of a novel object in detriment of the already known, it is possible to calculate an index of discrimination using the proportion of time the animal spends investigating a novel object compared to that familiar. A wide range of evidences obtained from studies in rodents lesions involve perirhinal cortex as the brain region necessary for the recognition of a new object, based on visual cues [42] whereas detections of a new object based in suggestions require use of hippocampus function, parahippocampal cortex, and entorhrinal cortex [43]. Following this line of reasoning, the evidence obtained from this task in our experiments do not exclude a Fip action affecting the region of the cerebral cortex perirhinal since the task conducted used visual evidences.

Classical neurophysiologic studies including both injury and electrophysiological assessment in humans and animals have already shown that certain areas of the brain rich in GABA (amygdala, septum, hippocampus and entorhrinal cortex) play an important role in the memory processes $[44,45]$.

Experimental evidence demonstrates that in the progression of neurotoxic diseases a biochemical event precedes the structural alterations and permanent damage to the central nervous system [46]. In this regard, the concentration of acetylcholine ( $\mathrm{ACh}$ ) as well as $\mathrm{AChE}$ inhibitors is therapeutic tools to improve cognitive deficiencies associated with neurodegenerative diseases [38].

In this study there was a significant increase in blood AChE activity in adult pups of Fip group compared to control.
Changes in dynamics and activity in various neurotransmitters in the hippocampal formation show that some mediators of the learning and memory process, including Ach, play an important role in memory formation in the hippocampus. This is possible to be discovered by preventing the learning/memory following administration of antagonists of respective mediators [47]. According to Schmatz et al. [48], changes in AChE activity has been associated with damage to learning and memory.

Data from the literature regarding the effect of fipronil on biochemical changes, including the activity of AChE, are rare. Dumka and Gill [49] exposed buffalo calves to $0.5 \mathrm{mg} / \mathrm{kg} /$ day dose of fipronil, orally for 98 days, and observed no significant change in AChE activity while Gupta et al. [50] which exposed carp (Cyprinus carpio) to Fip in concentrations of $0.01,0.1,1.0$ and $10 \mathrm{mg} / \mathrm{L}$ observed a significant reduction (approximately 50\%) in AChE in the brain of these animals. Despite the differences in the profile of experiments, the results obtained in this study with lactational exposition to fipronil, do not corroborate with the data obtained by Gupta et al. [50] and Gill and Dumka [41].

In this study, the increased AChE activity leading to an Ach reduction in adult rats could be implicated in the loss of memory behavior, as observed in 8-RAM and ORT tasks.

The participation of cholinergic system in the learning and memory is well documented. Briefly, results obtained by Castro et al. [51] and Winters et al. [20] indicate an important role for cholinergic tone in motor learning and object recognition memory, suggesting a participation of Ach on memory process. The ORT tasks are capable of inducing synaptic modifications and promoting long-term potentiation in hippocampus [52] and still, provoke increase of Ach liberation [53]. In the present experiments the observed toxicity of Fip on AChE enzyme could have influenced the cholinergic transmission in the CNS modifying memory behavior.

Neurotoxic agents can cause brain injury, especially if the exposures occur during the early development period. If the process of the nervous system development of immature embryo are impaired, the effects tend to be of long duration and possibly permanent [53]. This could be the situation that occurred in this experiment of perinatal exposure to fipronil.

In this study, histological evaluation in the brains of pups exposed to fipronil showed that both young animals as adults had distinct morphological changes including vascular congestion, edema and vacuolization. These morphological changes occurring in several areas of the brain could lead to the impairment of brain functions, including those related to memory behavior.

The lack of literature data about fipronil toxicity on memory behavior difficult a comparison of our results but on the other hand enhances the aggregate value of this study demonstrating a correlation between fipronil pesticide and memory defects. At last, findings provide a strong argument that future studies examining effects and mechanisms of developmental fipronil exposure on brain/behavioral development ought to be designed. A suggestion for an alternative strategy to investigate the mechanistic action of the effects here observed, is to attempt to act on Cl-transporters that determine the effects of GABA, and on cholinergic transmission in the CNS. 


\section{Conclusion}

Fipronil impacted the neurobehavioral development of rats exposed during the lactational period, causing damage to memory behavior, at short- and long-term, demonstrating a persistent neurotoxic effect. The data offer speculation that the observed damage on memory behavior can be related to the alterations on cholinergic functions but are insufficient to explain it. The histopathological alterations in brain suggest altered functional status in cerebral areas. Still, memory behavior facilitates the finding of potential prediction model for developmental neurotoxicity. These findings together may be a contribution to strengthen the hypothesis of a suggested relation between environmental pesticides and neurodegenerative diseases in which exists damage on memory behavior.

\section{Acknowledgement}

This work was supported by the CAPES and FAPESP (process 2013/17384-6 and 2013/16195-5) scholarships.

\section{References}

1. De Souza A, Medeiros Ados R, De Souza AC, Wink M, Siqueira IR, et al. (2011) Evaluation of the impact of exposure to pesticides on the health of the rural population: Vale do Taquari, State of Rio Grande do Sul Brazil. Cien Saude Colet 16: 3519-3528.

2. Mostafalou S, Abdollahi M (2012) Concerns of environmental persistence of pesticides and human chronic diseases. Clin Exp Pharmacol. S5: e002.

3. Tingle CCD, Rother JA, Dewhurst CF, Lauer S, King WJ (2003) Fipronil: Environmental fate, ecotoxicology, and humam health concerns. Rev Environ Contam Toxicol 176: 1-66.

4. Wilde GE, Whitworth RJ, Claassen M, Shufran RA (2001) Seed treatment for control of wheat insects and its effect on yield. J Agric. Urban Entomol 18: 1-11.

5. Jennings KA, Canerdy TD, Keller RJ, Atieh BH, Doss RB, et al. (2002) Human exposure to fipronil from dogs treated with frontline. Vet Hum Toxicol 44: 301-303.

6. Das PC, Cao Y, Cherrington N, Hodgson E, Rose RL (2006) Fipronil induces CYP isoforms and cytotoxicity in human hepatocytes. Chem Biol Interact 164: 200-214.

7. IPCS - International Programme on Chemical Safety (2001) Environmental health criteria 223. Neurotoxicity risk assessment for human health: principles and approaches. Geneva: World Health Organization (WHO), ISBN 944157223 X.

8. Katz RJ, Liebler L (1978) GABA involvement in memory consolidation: evidence from posttrial amino-oxyacetic acid. Psychopharmacology (Berl) 56: 191-193.

9. Menzies L, Ooi C, Kamath S, Suckling J, McKenna P, et al. (2007) Effects of gamma-aminobutyric acid-modulating drugs on working memory and brain function in patients with schizophrenia. Arch Gen Psychiatry 64: 156-167.

10. Cammarota M, Bevilaqua LR, Rossato JI, Ramirez M, Medina JH, et al (2005) Relationship between short- and long-term memory and shortand long-term extinction. Neurobiol Learn Mem 84: 25-32.

11. Michels L, Martin E, Klaver P, Edden R, Zelaya F, et al. (2012) Frontal GABA levels change during working memory. PLoS One 7: e31933.

12. Matsuda K, Buckingham SD, Kleier D, Rauh JJ, Grauso M, et al. (2001) Neonicotinoids: Insecticides acting on insect nicotinic acetylcholine receptors. Trends Pharmacol Sci 22: 573-580.

13. Zhao X, Yeh JZ, Salgado VL, Narahashi T (2005) Sulfone metabolite of fipronil blocks ? - Aminobutyric acid and glutamate-activated chloride channels in mammalian and insect neurons. J. Pharmacol. Exp. Ther 314: 363-373.
14. Ikeda T, Zhao X, Nagata K, Kono Y, Shono T, et al. (2001) Fipronil modulation of gamma-aminobutyric acid(A) receptors in rat dorsal root ganglion neurons. J Pharmacol Exp Ther 296: 914-921.

15. Ratra GS, Erkkila BE, Weiss DS, Casida JE (2002) Unique insecticide specificity of human homomeric rho $1 \mathrm{GABA}(\mathrm{C})$ receptor. Toxicol Lett 129: 47-53.

16. Stanley EM, Wilson MA, Fadel JR (2012) Hippocampal neurotransmitter efflux during one-trial novel object recognition in rats. Neurosci Lett 511: 38-42.

17. Schliebs R, Arendt T (2011) The cholinergic system in aging and neuronal degeneration. Behav Brain Res 221: 555-563.

18. De Jaeger X, Cammarota M, Prado MA, Izquierdo I, Prado VF, et al. (2013) Decreased acetylcholine release delays the consolidation of object recognition memory. Behav Brain Res 238: 62-68.

19. Palmer D, Creighton S, Prado VF, Prado MAM, Choleris E, et al. (2016) Mice deficient for striatal Vesicular Acetylcholine Transporter (VAChT) display impaired short-term but normal long-term object recognition memory. Behav Brain Res 31: 267-278.

20. Connors SL, Levitt P, Matthews SG, Slotkin TA, Johnston MV, et al. (2008) Fetal mechanisms in neurodevelopmental disorders. Pediatr Neurol 38: 163-176.

21. London L, Beseler C, Bouchard MF, Bellinger DC, Colosio C, et al. (2012) Neurobehavioral and neurodevelopmental effects of pesticide exposures. Neurotoxicology 33: 887-896.

22. Shelton JF, Geraghty EM, Tancredi DJ, Delwiche LD, Schmidt RJ, et al. (2014) Neurodevelopmental disorders and prenatal residential proximity to agricultural pesticides: The CHARGE Study. Environ. Health Perspect 122: 1103-1109.

23. Wagner-Schuman M, Richardson JR, Auinger P, Braun JM, Lanphear BP, et al. (2015) Association of pyrethroid pesticide exposure with attentiondeficit/hyperactivity disorder in a nationally representative sample of USA. children. Environ. Health 14: 44-51.

24. Jackson D, Cornell CB, Luukinen B, Buhl K, Stone D (2009) Fipronil technical fact sheet, national pesticide information center, Oregon State University extension services. In: http://npic.orst.edu/ factsheets/ fiptech.pdf.

25. Hovda LR, Hooser SB (2002) Toxicology of newer pesticides for use in dogs and cats. Vet Clin North Am Small Anim Pract 32: 455-467.

26. Dix SL, Aggleton JP (1999) Extending the spontaneous preference test of recognition: evidence of object-location and object-context recognition. Behav Brain Res 99: 191-200.

27. Olton DS (1987) The radial arm maze as a tool in behavioral pharmacology. Physiol Behav 40: 793-797.

28. Snedecor GW, Cochran WG (1991) Statistical Methods (8thedn) Wiley.

29. Smart JL, Dobbing J (1971) Vulnerability of developing brain. II. Effects of early nutritional deprivation on reflex ontogeny and development of behaviour in the rat. Brain Res 28: 85-95.

30. Salvatori F, Talassi CB, Salzgeber SA, Spinosa HS, Bernardi MM (2004) Embryotoxic and long-term effects of cadmium exposure during embryogenesis in rats. Neurotoxicol Teratol 26: 673-680.

31. Chernoff N, Rogers EH, Gage MI, Francis BM (2008) The relationship of maternal and fetal toxicity in developmental toxicology bioassays with notes on the biological significance of the no observed adverse effect level'. Repr Toxicol 25: 192-202.

32. Kimmel C (1998) Current approaches to risk assessment for developmental neurotoxicology. In Slikker W, Chang L. (eds.) Handbook of Developmental Neurotoxicology. San Diego: Academic Press 675-685.

33. Chelonis JJ, Flake RA, Baldwin RL, Blake DJ, Paule MG (2004) Developmental aspects of timing behavior in children. Neurotoxicol Teratol 26: 461-476.

34. Costa LG, Aschner M, Vitalone A, Syversen T, Soldin OP (2004) Developmental neuropathology of environmental agents. Annu Rev Pharmacol Toxicol 44: 87-110.

35. Lynch MA (2004) Long-term potentiation and memory. Physiol Rev 84: 87-136. 
Citation: Montanha FP, Machado FD, Faria CA, Anselmo F, Lot RFE, et al. (2016) Lactational Exposure to Fipronil Pesticide in Low Dose Impairs Memory in Rat's Offspring. J Neurol Disord 4: 279. doi:10.4172/2329-6895.1000279

Page 7 of 7

36. Hu Y, Xia Z, Sun Q, Orsi A, Rees D (2005) A new approach to the pharmacological regulation of memory: Sarsasapogenin improves memory by elevating the low muscarinic acetylcholine receptor density in brains of memory-deficit rat models. Brain Res 1060: 26-39.

37. Da Silveira CK, Furini CR, Benetti F, Monteiro Sda C, Izquierdo I (2013) The role of histamine receptors in the consolidation of object recognition memory. Neurobiol Learn Mem 103: 64-71.

38. Rudolph U (2015) Diversity and functions of GABA receptors: A tribute to Hanns Möhler, Part A. In: Advances in Pharmacology. London, Academic Press 73: 1-270.

39. Rudolph U (2015) Diversity and functions of GABA receptors: A tribute to Hanns Möhler, Part B. In: Advances in Pharmacology. London, Academic Press 73: 1-270.

40. Ennaceur A (2010) One-trial object recognition in rats and mice: Methodological and theoretical issues. Behav Brain Res 215: 244-254.

41. Albasser MM, Chapman RJ, Amin E, Iordanova MD, Vann SD, et al (2010) New behavioral protocols to extend our knowledge of rodent object recognition memory. Learn Mem 17: 407-419.

42. Barker GR, Warburton EC (2011) When is the hippocampus involved in recognition memory? J Neurosci 31: 10721-10731.

43. Rawling JNP (1987) Do hippocampal lesions produce amnesia in animals? In: Stahl, SM, Iversen SD, Goodman EC. (eds.) Cognitive Neurochemistry. Oxford: Oxford University Press 73-89.

44. Davis M (1994) The role of the amygdala in emotional learning. Int Rev Neurobiol 36: 225-266.

45. Kamel F, Hoppin JA (2004) Association of pesticide exposure with neurologic dysfunction and disease. Environ Health Perspect 112: 950-958.
46. Dere E, Huston JP, De Souza Silva MA (2007) The pharmacology, neuroanatomy and neurogenetics of one-trial object recognition in rodents. Neurosci Biobehav Rev 31: 673-704.

47. Schmatz R, Mazzanti CM, Spanevello R, Stefanello N, Gutierres J (2009) Resveratrol prevents memory deficits and the increase in acetylcholinesterase activity in streptozotocin-induced diabetic rats. Eur. J. Pharmacol 610: 42-48.

48. Gill KK, Dumka VK (2013) Biochemical alterations induced by oral subchronic exposure to fipronil, fluoride and their combination in buffalo calves. Environ. Toxicol. Pharmacol. 36: 1113-1119.

49. Gupta SK, Pal AK, Sahu NP, Saharan N, Prakash C, et al. (2014) Haemato-biochemical responses in Cyprinus carpio (Linnaeus, 1758) fry exposed to sub-lethal concentration of a phenylpyrazole insecticide, fipronil. Proc Nat Acad Sci, India, Section B: Biological Sciences 84: 113-122.

50. Castro BM, Pereira GS, Magalhães V, Rossato JI, De Jaeger X, et al. (2009) Reduced expression of the vesicular acetylcholine transporter causes learning deficits in mice. Genes, Brain and Behav 8(1): 23-35.

51. Clarke JR, Cammarota M, Gruart A, Izquierdo I, Delgado-Garcia JM (2010) Plastic modifications induced by object recognition memory processing. Proc Natl Acad Sci USA 107: 2652-2657.

52. Degroot A, Wolff MC, Nomikos GG (2005) Acute exposure to a novel object during consolidation enhances cognition. Neuroreport 16: 63-67.

53. Julvez J, Grandjean P (2009) Neurodevelopmental toxicity risks due to occupational exposure to industrial chemicals during pregnancy. Industrial Health. 47: 459-468. 